\title{
Supporting Teachers on Their STEAM Journey: A Collaborative STEAM Teacher Training Program
}

\author{
Katherine L. Boice*(D, Justina R. Jackson (D, Meltem Alemdar, Analía E. Rao, Sabrina Grossman and \\ Marion Usselman
}

Citation: Boice, K.L.; Jackson, J.R.; Alemdar, M.; Rao, A.E.; Grossman, S.; Usselman, M. Supporting Teachers on Their STEAM Journey: A Collaborative STEAM Teacher Training Program. Educ. Sci. 2021, 11, 105. https://doi.org/10.3390/ educsci11030105

Academic Editor: Ileana Maria Greca

Received: 12 February 2021

Accepted: 2 March 2021

Published: 5 March 2021

Publisher's Note: MDPI stays neutral with regard to jurisdictional claims in published maps and institutional affiliations.

Copyright: (c) 2021 by the authors. Licensee MDPI, Basel, Switzerland. This article is an open access article distributed under the terms and conditions of the Creative Commons Attribution (CC BY) license (https:// creativecommons.org/licenses/by/ $4.0 /)$.
Center for Education Integrating Science, Mathematics, and Computing (CEISMC), Georgia Institute of Technology, Atlanta, GA 30332, USA; justina.jackson@ceismc.gatech.edu (J.R.J.); meltem.alemdar@ceismc.gatech.edu (M.A.); analia.rao@ceismc.gatech.edu (A.E.R.); sabrina.grossman@ceismc.gatech.edu (S.G.); marion.usselman@ceismc.gatech.edu (M.U.)

* Correspondence: katherine.boice@ceismc.gatech.edu

\begin{abstract}
There is growing enthusiasm for STEAM education in preparing students for an increasingly complex world. However, implementing STEAM in the classroom can be challenging for educators, as it may require collaboration across disciplines, increased workload, and understanding the nature of STEAM integration. This paper details a mixed-methods evaluation of a year-long STEAM teacher training program, in which a STEM teacher and an arts teacher collaborated to design and implement integrated STEAM lessons at each of the nine participating schools $(n=17)$. The training program consisted of a 5-week summer professional development experience, followed by ongoing financial, material, and pedagogical support during the school year, made possible by the partnership of the schools, a university, and community organizations. Findings from surveys, focus groups, and written reflections suggest that, despite certain challenges, aspects of the training program supported teacher implementation of STEAM. Participation in the program impacted teachers collaboration, pedagogy, self-efficacy, and arts integration practices. The findings offer insight into the forms of support that teachers deem important in STEAM teacher training programs and the benefits of such a program for teachers' professional development.
\end{abstract}

Keywords: STEAM education; teacher training; program evaluation

\section{Introduction}

In a modern, increasingly complex world, America's teachers are tasked with producing students who are able to solve increasingly complex problems. In recent years, Science, Technology, Engineering, Arts, and Math (STEAM), a melding of the now-familiar acronym "STEM" with integration of the arts, has emerged as a potentially useful tool in this challenge [1]. However, STEAM is often poorly defined with varying levels of implementation [2,3]. Furthermore, STEAM can be difficult to implement, with teachers reporting challenges with, among other things, collaboration across disciplines, increased workload, and understanding STEAM integration [4-8].

The GoSTEAM@Tech teacher training program is a partnership between the Georgia Institute of Technology ("Georgia Tech"), preK-12 schools in the metro-Atlanta area, and arts-focused community organizations. The program was conceived of as a way to better define the field of STEAM and mitigate the challenges of implementing STEAM by working with teachers and creative community members to develop, pilot, and evaluate welldefined and disseminatable STEAM-focused lessons and activities. The partnership is led by Georgia Tech's Center for Education Integrating Science, Mathematics, and Computing (CEISMC) and specifically focuses on integrating, in authentic and compelling ways, the technical fields of Computer Science, Engineering, and Invention and Entrepreneurship with the arts, including Visual Arts, Media Arts, Dramatic Arts/Theatre, Dance and Music. 
The unit of operation in GoSTEAM@Tech is the school-based STEAM Innovation Team. Each STEAM Innovation Team consists of at least two teachers-with at least one from a STEM field and one from an arts field-partnered with a creative innovator-inresidence ("innovator"), and an academic coach from CEISMC. Innovators are members of the community, often associated with the Makers movement or educational programs like Georgia Tech's Music Technology program or local Design schools, who are employed for $20 \mathrm{~h}$ per week in residence at the school. The CEISMC coaches are experienced educators who have worked with teachers in professional development (PD) settings and who have substantial experience in developing STEAM curriculum. While participating in the GoSTEAM@Tech program, teachers attended a five-week summer PD experience and received ongoing financial, material, and pedagogical support throughout the school year.

\subsection{GoSTEAM@Tech Evaluation}

During its pilot year, the GoSTEAM@Tech program was implemented with 17 teachers across nine schools. A mixed-methods evaluation was conducted to assess program functioning and potential outcomes of participation, with Developmental Evaluation and Utilization-Focused Evaluation serving as the guiding frameworks for the evaluation. Developmental Evaluation, with its emphasis on adapting to context and supporting "program, project, product, personnel and/or organizational development" complements the flexible nature of the program's interventions, which are designed to accommodate the unique needs and strengths of each participating school (e.g., existing resources and capacity) [9] (p. 317). The Utilization-Focused Evaluation framework was used as a complementary framework, because it centers evaluation on "intended use by intended users" and therefore lends itself to "situational responsiveness" [10] (p. 37). This situational responsiveness increases the likelihood that evaluation will be meaningful to those in a specific context (in our case, GoSTEAM@Tech program leadership), and therefore more likely to be utilized. Given the context-specific approach of the GoSTEAM@Tech program intervention, as well as the novelty of STEAM education and interventions, the Developmental Evaluation and Utilization-Focused Evaluation frameworks allow for flexibility in evaluation as program theory evolves.

The current program theory is illustrated in the logic model below, which outlines the resources that supported program activities, and the proposed outputs and outcomes of participation in the GoSTEAM@Tech program (Figure 1). Though the evaluation focuses on collecting both formative and summative data to show the influence of the program on teachers and students, the purpose of this paper is to describe the experience of participating teachers during the pilot year. Specifically, we explore elements of the training program that teachers deem important, the influence of participation on teachers' perceptions and pedagogical practices, challenges faced by participating teachers, and how professional learning programs can be designed to mitigate these challenges.

\subsection{Literature Review}

In recent years, there has been an uptick in STEAM publications, demonstrating a growing interest in STEAM education from researchers and practitioners alike [11]. The increasing interest in STEAM education has been met with calls for a "coherent base of scholarship" [3] (p. 73). to define STEAM and recommendations for scholars to clarify their own definitions of STEAM [2,3]. Thus, we briefly summarize some existing conceptualizations of STEAM, which we used to formalize our own working definition. Then, we present literature on the challenges of implementing STEAM initiatives and documented outcomes of existing STEAM PD programs.

\subsubsection{STEAM: An Emerging Field}

Promising studies of STEAM curricula and activities implemented in K-12 settings have demonstrated increases in students' STEM content knowledge, an intent to continuing studying or participating in STEAM, more positive attitudes towards STEAM, and 
improved gender dynamics in the classroom [12-16]. Similar outcomes have been documented for students participating in STEAM initiatives in summer camps, museums, and after-school settings [11,17-19]. STEAM is being used across the globe in an effort to improve student outcomes in STEAM disciplines [20].

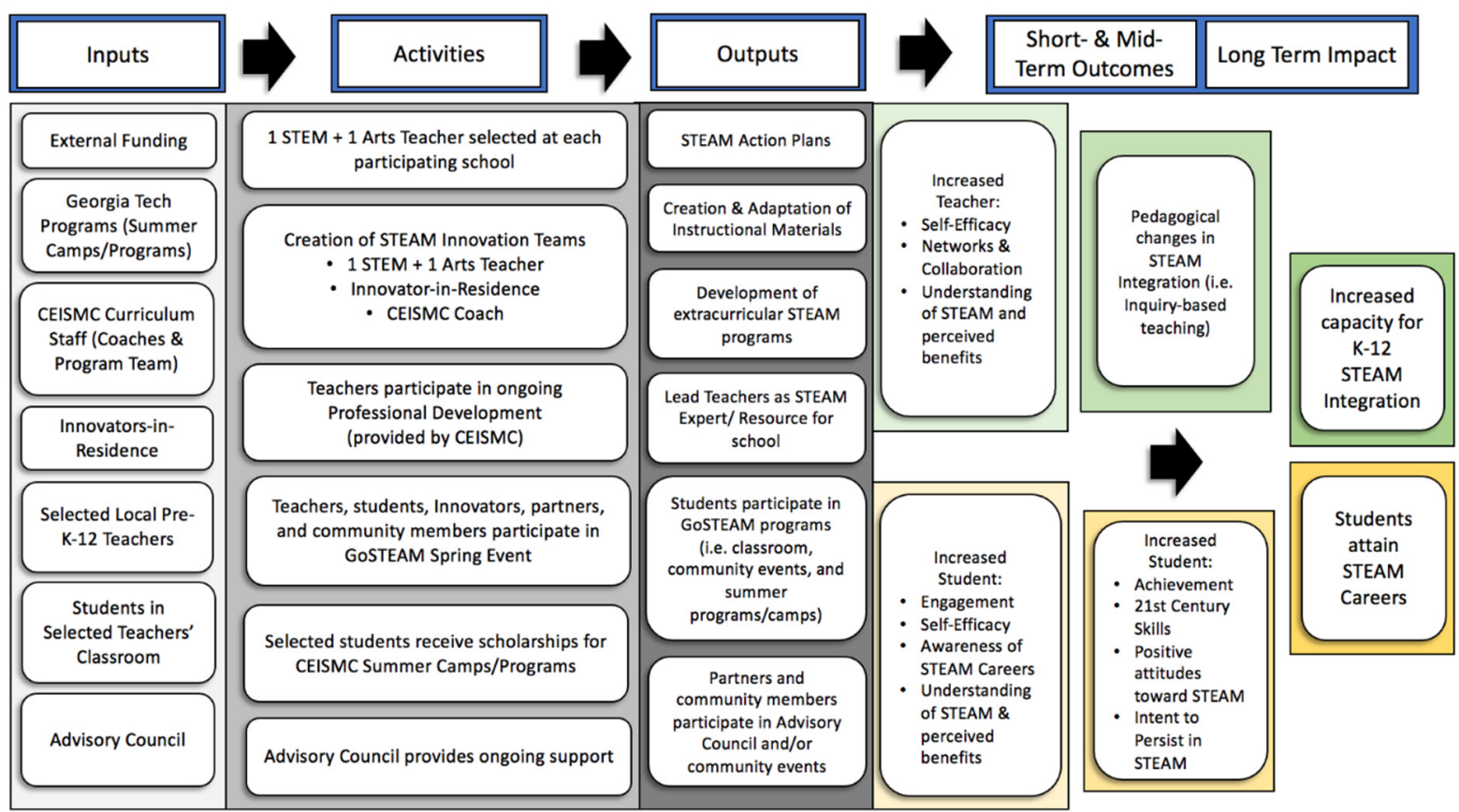

Figure 1. GoSTEAM@Tech Logic Model.

There are shared characteristics that link these STEAM initiatives together, such as the integration of multiple disciplines, focus on real-world problems, collaboration, student-directed work, project-based instruction, or problem-based inquiry learning (PBIL). However, perspectives on how to conceptualize STEAM vary, with differing perspectives on the purpose, nature of discipline integration, and the role of the arts in STEAM [20-22]. For example, studies of STEAM around the globe have found that some view STEAM as a mechanism for advancing learning, interest, or engagement in STEM disciplines, while others use STEAM to focus on enhancing the arts [20-22]. This is further complicated by many definitions of the "A" in STEAM, which can serve as a proxy for 21st century skills, such as creativity and problem-solving, or for teaching strategies commonly associated with STEAM, such as problem- or project-based learning, technology-based learning, or Making [21,22]. The muddied role of the arts in STEAM has caused some to advocate for art educators play a prominent role in STEAM initiatives to preserve the dignity of arts disciplines and STEM disciplines and prevent the arts from playing a "subservient" role in the name of STEM education [23] (p. 5) [3,19,22,24]. Some authors go beyond a focus on the interplay of individual STEAM disciplines, conceptualizing STEAM as a transdisciplinary instructional approach drawing on discipline integration, characteristics of the classroom environment, and problem-solving skills [25].

\subsubsection{Challenges of STEAM}

Just as scholars struggle to operationalize STEAM, practitioners face challenges interpreting and enacting STEAM in their classrooms. This can result in an over-simplified understanding of STEAM, with teachers interpreting STEAM as a series of activities and tasks rather than a holistic approach to learning [7]. Even after participating in a semesterlong course on STEAM integration, teachers in one study reported concern about their lack of experience with STEAM and continued confusion about integrating particular disciplines within STEAM [4]. The inclusion of multiple disciplines in STEAM education presents challenges for teachers collaborating across disciplines [6]. Common planning 
time can ease these challenges, but teachers report difficulties arranging time to plan collaboratively, and even to plan independently, with some citing concerns about an increased workload $[5,7,8]$. Additionally, students are often encouraged to collaborate on STEAM projects, which can be a challenge for teachers to facilitate [6]. STEAM typically incorporates instructional practices, such as problem, project-, or inquiry-based learning, that can be challenging for teachers to implement, as they require teachers to move away from direct instruction and towards a facilitator role supporting student-led exploration [26,27]. Teachers have also expressed concerns about including appropriate standards in STEAM projects, ensuring students meet those standards, and pacing lessons and activities appropriately $[7,8,28]$. Multiple studies have found that teachers face challenges determining authentic assessment strategies for students, given the frequent use of collaboration among students, the iterative nature of STEAM projects, and the inclusion of multiple disciplines, some of which may be outside the scope of the teachers' usual subjects $[6,8,28,29]$.

\subsubsection{STEAM Professional Development}

STEAM PD experiences can grow teachers' interest in implementing STEAM in their classrooms and their enjoyment teaching STEAM lessons [30,31]. More importantly, studies of STEAM PD opportunities have identified positive pedagogical benefits for participants, such as increased confidence planning and implementing STEAM lessons, integration of technology in instructional approaches, the use of authentic assessment, and connecting with resources and experts outside the school building to support STEAM instruction $[6,30,32]$. A recent study of intensive STEAM interventions in teacher populations suggests that STEAM can have positive effects on the classroom environment and teachers' pedagogical discontentment when teachers have ample, ongoing support [33]. Pedagogical discontentment is a disconnect between a teacher's goals for their own pedagogy and their actual classroom practices. In the context of STEAM, the authors suggest that teachers without the content knowledge or pedagogical skills associated with STEAM teaching can experience pedagogical discontentment as they work to implement STEAM. After $80 \mathrm{~h}$ of PD and a year of partnership with STEAM coaches, participating K-12 teachers demonstrated significant decreases in pedagogical discontentment, as well as positive changes to classroom environments to be more supportive of STEAM instruction [33]. These findings highlight the benefits of participating in STEAM training, as well as the importance of continuous support for teachers as they work to integrate STEAM into their classrooms.

In this article, we respond to the calls to clearly define STEAM within our context by offering our own working definition, as well as highlighting teachers' perspectives on the nature of arts integration within their STEAM projects. In doing this, we recognize the validity of a range of conceptualizations of STEAM, their unique purposes, and the important role of teachers in defining the STEAM approach that works best in their classroom. In addition, this article contributes to the literature on STEAM PD. The STEAM teacher training described here addresses a number of challenges reported in the literature, such as collaboration across disciplines and the need for ongoing support as teachers take STEAM lessons back to their classrooms. Outcomes of participating in the teacher training experience are shared, in addition to the challenges that teachers experience while designing and implementing STEAM lessons, as well as the support mechanisms that mitigate these challenges.

\subsection{Program Context}

The GoSTEAM@Tech program provides both training and support to teachers through the following mechanisms: (1) a five-week summer PD and (2) ongoing, year-long, systemic support embedded in the context of their respective schools. These components have shared goals of providing teachers with pedagogical content knowledge in STEAM education and supporting the design and implementation of STEAM lesson plans. The summer PD provides a broad focus on STEAM in the classroom while building enthusiasm and 
collaboration. The year-long support is more targeted and school-specific, with an emphasis on lesson implementation.

\subsubsection{Summer Professional Development}

During the pilot year of the GoSTEAM@Tech teacher training program, the summer PD included one week of online self-paced learning followed by four weeks of face-to-face learning. The PD goals were for teachers to learn the foundation of STEAM pedagogy, increase their cross-disciplinary content knowledge, develop interdisciplinary instructional materials, and plan for school year implementation of a STEAM Action Plan. The PD was a mixture of whole group instruction, school district-specific meetings, and school team collaborations.

A total of 17 teachers from nine schools across three school districts participated in the 2019 summer PD experience. Seven of the nine innovators were able to join the teacher PD to learn about STEAM and to work closely with the teachers as they planned STEAM activities and lessons. Both teachers and innovators started the PD by completing a 10-h Project-Based Inquiry Learning (PBIL) course online. This asynchronous course included introductory readings and discussion about PBIL and best practices in the STEAM classroom. GoSTEAM@Tech staff provided online support for the inquiry course. An important function of this course was to provide participants with shared language and pedagogies as they learned content outside of their disciplinary focus. Using project-based learning to engage teachers across disciplines, they applied authentic scenarios to cross disciplinary boundaries and create new knowledge [34]. The course also allowed teachers to introduce themselves to their fellow cohort members.

The first week of the face-to-face PD session introduced teachers to the GoSTEAM@Tech program and built their STEAM literacy skills. Significant time was spent on team building, as this was the first opportunity for teachers, innovators, and coaches to collaborate in person. In the following weeks, teachers and innovators engaged in authentic STEAM hands-on activities (i.e., puppetry, paper mechatronics, coding), and heard from Georgia Tech faculty and other invited speakers about cutting-edge STEAM research, assessment practices, and culturally authentic teaching practices. They also toured campus facilities and visited local community arts organizations to see examples of authentic STEAM environments and build connections with community resources that could support their STEAM PBIL lessons.

During the PD, we provided teachers with a working definition of STEAM to guide their exploration of STEAM education. As previously described, there is no single, cohesive definition of STEAM, nor is there an established set of best practices articulated in the literature [2,3]. Therefore, we instead looked for "high-quality lessons learned" [35] (p. 334) within the STEAM literature when defining STEAM within the context of the GoSTEAM@Tech program. In addition, we drew on existing models of integration, including Bresler's model of arts integration [23] and the National Research Council's STEM integration framework [36]. Through this, we developed a working definition of high-quality STEAM instruction, which involves utilizing student-centered instructional pedagogies, including PBIL, group learning, and real-world application, to increase cross-disciplinary content knowledge through learning goals for students in both STEM and arts disciplines. This definition allowed us to establish a shared understanding of high-quality STEAM among teachers. However, we recognize the complexity and challenges of STEAM implementation. Thus, we envision STEAM as a continuum, moving from low to high levels of integration, collaborative practices, and complexity of STEAM projects. The goal of our teacher training was to help teachers move along this continuum towards high-quality STEAM by providing targeted PD and ongoing support as teachers designed and implemented STEAM lessons in their classrooms.

At the end of the summer PD, teachers submitted a STEAM Action Plan, which was a formal document that outlined a lesson or unit project that collaborating teachers planned to implement in their classrooms the following year. It included documentation of student- 
centered pedagogies, standards from STEM and the arts, and the nature and scope of STEAM integration. Teachers started working on their Action Plan during the first week of PD and were encouraged to use pedagogies and activities modeled throughout the PD to inspire their Action Plan development. Coaches also provided teams with resources and guidance as they worked collaboratively to design their STEAM Action Plan. An important part of the Action Plan development process was to evaluate each team's current school and classroom contexts. Teachers conducted a SWOT (Strengths, Weaknesses, Opportunities, and Threats) analysis of their school and community, toured their schools with coaches and innovators, and connected with community resources. Understanding school scheduling, pacing, access to technology, and student demographics allowed the teachers to design with intention, giving them greater success in plan implementation [6]. Each STEAM Innovation Team (teachers, innovators, and coaches) presented their Action Plans at a PD showcase on the final day of the program, receiving feedback from other teachers and celebrating their work during the PD.

\subsubsection{Ongoing Support}

Embedded school-year support, as modeled by Thompson and colleagues, continued to facilitate the learning from the summer PD experience [33]. Each GoSTEAM@Tech coach worked with three schools to continue to develop STEAM literacy and support teachers as they implemented their Action Plans. They met bi-weekly with each school to discuss the design and implementation of the Action Plan and other school STEAM initiatives. Coaches served as pedagogical and content experts for each GoSTEAM@Tech pathway (Computer Science, Engineering, and Invention and Entrepreneurship), and thus were able to model lessons for teachers or provide instructional feedback after class observations. They also served as mentors providing emotional support and encouragement to the teachers as they navigated challenges in their school environment. As part of the GoSTEAM@Tech model, teachers also received support from innovators, who spent $20 \mathrm{~h}$ a week supporting teachers with planning and implementation. Innovators had access to Georgia Tech resources and to the expertise of other innovators as they developed strategies and ideas to support their teachers. Program staff provided financial support and materials for teachers to implement STEAM projects in their classrooms. Staff also conducted classroom visits (both face-to-face and virtual) to provide feedback to teachers on their projects and engage students with Georgia Tech and GoSTEAM@Tech initiatives. To cultivate a culture of ongoing collaboration, the program staff also sent out a weekly newsletter with resources and PD opportunities provided by local and national STEM/STEAM organizations. In addition to financial support for material resources, GoSTEAM@Tech provides funding for teachers to attend PD and STEAM-related professional conferences. For example, during the 2019-2020 school year, GoSTEAM@Tech teachers received program funds to attend workshops hosted by the Computer Science Teacher Association, the Alliance Theatre (local arts organization), and Georgia Science Teachers Association. These opportunities provided personalized and relevant PD to meet teachers' needs as they developed and implemented STEAM lessons. Additional support was also made available to schools through the GoSTEAM@Tech Advisory Council. This group is currently composed of 25 arts and education leaders from Georgia Tech and the broader community. GoSTEAM@Tech staff facilitated interactions between teachers and Advisory Council members, enabling teachers to access this group for field trips and guest speaker opportunities.

\section{Materials and Methods}

This evaluation of the GoSTEAM@Tech program was designed to capture information on the experiences of teachers participating in STEAM PD, as well as outcomes of participation. Accordingly, a descriptive case study using a mixed-methods triangulation design was utilized to combine the collection and analysis of quantitative surveys and qualitative focus groups/interviews and open-ended survey questions $[37,38]$. This approach allowed for the inclusion of multiple stakeholder perspectives on the program and its outcomes in 
the pilot year. Data collection was ongoing, beginning before teachers participated in the summer component of the PD experience and continuing through the end of the following school year. This enabled us to assess changes in teachers' perceptions and practices related to STEAM education. The evaluation was guided by the following questions:

- What do teachers consider to be the important elements of a STEAM teacher training experience designed to support the creation and implementation of STEAM PBIL lessons?

- How does participating in a STEAM training experience influence teachers' perceptions and practices related to collaboration, pedagogy, self-efficacy, and arts integration?

- What are the challenges of implementing STEAM PBIL activities in the classroom?

- How can a STEAM training program be designed to include support mechanisms that mitigate these challenges?

\subsection{Participants}

During its first and pilot year, 17 teachers participated in the GoSTEAM@Tech program. Teachers taught students at the elementary-school $(n=8)$, middle-school $(n=5)$, and high-school $(n=4)$ levels. One STEM-discipline teacher and one arts-discipline teacher participated at each school (with the exception of one school, which did not have a participating arts-discipline teacher). At the middle- and high-school levels, participating teachers taught a range of specialties, including theater, science, chorus, computer science, and engineering, for example. Among participating elementary-school teachers, some were specialists (e.g., STEM teacher, visual arts teacher), while others were generalists, providing instruction in multiple "core" subjects (i.e., social studies, language arts, math, and science). When a teacher pair included a general education teacher, the generalist teacher contributed their knowledge of STEM standards at the relevant grade level. Additionally, three participants were instructional coaches rather than classroom teachers. These participants collaborated with classroom teachers at their schools to implement integrated STEAM lessons with students. For simplicity, all 17 participants are hereafter referred to as "teachers." Participants were both novice and veteran teachers, with between two years and two decades of teaching experience, averaging nine years of experience. On average, teachers had taught at their current school for four years, though some had taught at their current school for up to 15 years.

\subsection{Measures}

Online surveys were administered to teachers at four time points during the pilot year of the GoSTEAM@Tech program. A Background Survey was administered in the Spring semester prior to the summer PD to capture formative baseline data on teachers' teaching practices and the conditions at their schools. A pre- and post-survey were administered on the first and last day of the summer PD experience to assess teachers' social networks and teaching self-efficacy (before PD) and their satisfaction with the experience and ongoing support needs (after PD). At the end of the school year, a final post-survey captured teachers' social networks, teaching practices, conditions at school, arts integration practices, experience in the program, and teaching self-efficacy. The surveys also included items to capture formative data. Due to the COVID-19 pandemic, all interviews and focus groups were conducted online at the end of the school year.

The teacher surveys were created using items from an existing validated measure of teaching self-efficacy (Cronbach's alpha $=0.94)$ [39]. The scale contained 24-items, which teachers responded to using a nine-point scale, ranging from "nothing" (1) to "a great deal" (9). The development of teacher networks through various forms of collaboration was investigated using social network questions. On the PD pre-survey, participants were given a list of other GoSTEAM@Tech teachers and asked to select the individuals with whom they had collaborated with during the past year, adding additional names of teachers, school personnel, or administrators as necessary. Next, for each person with whom 
they collaborated, participants selected the level of collaboration according to the following: Informal Information Exchange (briefly communicating ideas or stories about teaching in an informal way (e.g., hallway conversation or brief email)); Giving or Receiving Advice or Help (giving/asking for advice or help about teaching); Sharing Resources (sharing materials, methods, or ideas related to teaching (e.g., lesson plans)); Joint Work (working together to design or deliver instruction (e.g., co- teaching, planning a unit together) or working together to develop a solution to a problem related to teaching). Teachers completed the same exercise on the end-of-year post-survey. The number of collaborators, as well as the level of collaboration, were compared to assess potential changes in number of collaborators and manner of collaboration after one year of participation in the GoSTEAM@Tech program. Items assessing teachers' perceptions of arts integration were developed by the authors based on the existing arts integration and STEAM literature. In addition, survey items were developed by the authors to collect formative data on teachers' satisfaction with program elements, perceptions of support received from the program, and perceived impacts of program participation on their PBIL instructional practices.

Teacher focus group/interview protocols were designed to explore teachers' perceptions of the training they received, resulting pedagogical changes, and general experience with the STEAM training program. Focus groups/interviews were conducted during Spring of 2020 (January-May). Teachers from the same school were interviewed together, with the exception of one school where only one teacher participated in the GoSTEAM@Tech program and thus was interviewed alone.

\subsection{Ethics Approval}

The materials and methods utilized in this evaluation were approved by the University's Institutional Review Board (IRB), as well as the district-level IRB for each of the three participating schools. All participants provided voluntary informed consent. GoSTEAM@Tech evaluators and staff completed the Collaborative Institutional Training Initiative (CITI) certification, ensuring that everyone involved in the evaluation was familiar with principles and practices of ethical research.

\subsection{Data Analysis}

As this study used a mixed-methods design, a range of descriptive statistics were used to understand trends in quantitative data. Where sample sizes allowed, inferential statistics were used to analyze quantitative data. Qualitative data were analyzed using an iterative content thematic approach to examine meaning and patterns within the data [40]. Codes were assigned to portions of data and later organized into categories with the outcome of the process leading to a series of refined themes [41]. Social network analysis (SNA) was used to map network diagrams depicting changes in teacher collaboration networks, visualizing of the various forms of collaboration taking place throughout the study [42]. SNA is a method used to detect and interpret patterns of social ties among network actors such as teachers. While traditional social science methodologies assess outcomes based on variables associated with actors themselves, network theory is unique in that it examines the relationships between actors [42]. Network diagrams indicating the number of collaborators and the level of collaboration were compared to assess potential changes in the number of collaborators and manner of collaboration after one year of participation in the GoSTEAM@Tech program.

\section{Results}

\subsection{Teacher Perspectives on Important Elements of STEAM Teacher Training Program}

The GoSTEAM@Tech program was designed to provide professional learning experiences as well as year-long material and pedagogical support. The summer PD provided the foundation of pedagogical support for teachers participating in the program. During the PD, teachers had the opportunity to hear a variety of speakers, tour campus facilities, and gain hands-on experience with software, tools, and equipment for potential classroom 
use. Workshops on culturally relevant pedagogy and social justice in STEAM, PBIL, and training on STEAM technologies and resources (e.g., the music coding program EarSketch) received high satisfaction ratings from teachers immediately following the summer PD, with at least $90 \%$ of participants reporting that they were satisfied or very satisfied with these workshops. In addition, teachers often described these same workshops as helpful in end-of-year focus groups. Teachers also reported in focus groups that they appreciated the structure and format of the PD, which was described as a series of "master classes" and a "hands-on interactive experience." The hands-on aspect of the summer training allowed participants to develop their knowledge of STEAM pedagogy as learners and teachers, experiencing the activities similarly to how their students would experience them, with one teacher stating, "the more we can create, the better we're going to be, because we'll understand what the kids have to do." Teachers were given dedicated planning time to work with other members of their STEAM Innovation Teams to develop their Action Plans during the PD. Teachers reported that this collaboration helped them build relationships and develop plans that contributed to their success throughout the school year. Coaches and innovators were especially important for planning, as they provided ideas and feedback on teachers' initial STEAM Action Plans over the summer.

Following the summer PD, teachers received ongoing support as a part of their participation in the GoSTEAM@Tech training program, including funding for STEAM resources and materials, their coach, and their innovator. Funding for STEAM materials and fieldtrips supplemented teachers' Action Plans by providing unique exploration opportunities for students, opportunities which students otherwise might not have had because of their school's limited resources. Coaches and innovators remained active members of the STEAM Innovation Teams during the school year. At the end of the school year, teachers indicated high satisfaction on a 5-point scale with the support they received from their coach $(M=4.75, S D=0.58)$ and their innovator $(M=4.47, S D=0.74)$. On the end-of-year post-survey, teachers reported that both coaches and innovators provided feedback and ideas on STEAM lessons, but that the type of feedback and ideas differed, with coaches offering pedagogical support and content expertise, while innovators contributed ideas that were considered valuable for being "outside of the box", "creative", or from a perspective outside of the field of education. Additionally, teachers described different, but complimentary, forms of support provided by their coaches and innovators. Coaches provided broad, holistic support for teachers, answering questions, offering advice on Action Plans, helping connect teachers to resources at other schools or the university, and communicating with school administrators to advocate for teachers. Innovators, on the other hand, offered targeted classroom support to both teachers and students. They collaborated with teachers to provide curricular and instructional support and enhance classroom learning through the creation of standards-based content. Innovators worked directly with students to support Action Plan implementation by teaching new technologies and providing feedback to students, drawing on knowledge and technical expertise from their respective fields.

\subsection{Influence of STEAM Teacher Training Program on Teachers \\ 3.2.1. Arts Integration}

We explored teachers' perspectives on the nature of arts integration reflected in their Action Plans according to the GoSTEAM@Tech Integration Continuum developed by the authors (Figure 2). The majority of teachers reported equal integration of STEM and arts in their instructional practices, learning goals, mastery expectations, and assessment practices. Lower levels of integration were reported for teaching practices, with a majority of teachers reporting that they only taught content from their respective discipline, but made explicit connections to other disciplines. Additionally, some teachers reported that they were able to regularly co-teach or push into each other's GoSTEAM@Tech classes. 


\section{GOSTEAM INTEGRATION CONTINUUM}

\begin{tabular}{|c|c|c|}
\hline $\begin{array}{l}13 \% \\
\text { Instruction in one } \\
\text { discipline serves to } \\
\text { enhance or support } \\
\text { instruction in the other. }\end{array}$ & $\begin{array}{l}13 \% \\
\text { One discipline is dominant, but } \\
\text { instruction is given for disciplinary } \\
\text { content in both disciplines. }\end{array}$ & $\begin{array}{l}\mathbf{7 5 \%} \\
\text { Equal instruction is given } \\
\text { in both disciplines. }\end{array}$ \\
\hline $\begin{array}{l}\text { Learning goals are all } \\
\text { related to one discipline. }\end{array}$ & $\begin{array}{l}6 \% \\
\text { Learning goals are related to both } \\
\text { disciplines, but the majority of } \\
\text { learning goals are related to one } \\
\text { discipline. }\end{array}$ & $\begin{array}{l}94 \% \\
\text { Learning goals are related } \\
\text { to both disciplines } \\
\text { approximately equally. }\end{array}$ \\
\hline $\begin{array}{l}\text { Mastery is only expected } \\
\text { in one discipline. Only } \\
\text { engagement in the other } \\
\text { discipline is required. }\end{array}$ & $\begin{array}{l}44 \% \\
\text { Mastery is expected in one } \\
\text { discipline. In the other discipline, } \\
\text { satisfactory performance is } \\
\text { acceptable. }\end{array}$ & $\begin{array}{l}56 \% \\
\text { Mastery is expected in } \\
\text { both disciplines. }\end{array}$ \\
\hline $\begin{array}{l}6 \% \\
\text { Assessments are all } \\
\text { related to one discipline. }\end{array}$ & $\begin{array}{l}31 \% \\
\text { Assessments are related to both } \\
\text { disciplines, but majority of } \\
\text { questions/topics focus on one } \\
\text { discipline. }\end{array}$ & $\begin{array}{c}63 \% \\
\text { Assessments are related } \\
\text { to both disciplines } \\
\text { approximately equally. }\end{array}$ \\
\hline $\begin{array}{l}19 \% \\
\text { Teachers are responsible } \\
\text { for teaching content only } \\
\text { from their discipline. }\end{array}$ & $\begin{array}{l}\mathbf{5 6 \%} \\
\text { Teachers mainly teach content } \\
\text { from their discipline, but make } \\
\text { explicit connections to other } \\
\text { discipline. }\end{array}$ & $\begin{array}{l}\mathbf{2 5 \%} \\
\text { Teachers teach content } \\
\text { from both disciplines in } \\
\text { their respective classes. }\end{array}$ \\
\hline $\begin{array}{l}44 \% \\
\text { Teachers instruct target } \\
\text { students separately. }\end{array}$ & $\begin{array}{c}13 \% \\
\text { Teachers co-teach or push into } \\
\text { each other's classes occasionally } \\
\text { (less than half of implementation } \\
\text { period). }\end{array}$ & $\begin{array}{c}44 \% \\
\text { Teachers regularly co- } \\
\text { teach or push into each } \\
\text { other's classes during } \\
\text { implementation period. }\end{array}$ \\
\hline
\end{tabular}

Figure 2. GoSTEAM@Tech Integration Continuum and Teacher Ratings.

In focus groups, teachers also reflected on arts integration as part of their Action Plans, which, in some cases, corresponded to the levels of integration reflected in the GoSTEAM@Tech Integration Continuum. For example, in multiple focus groups teachers described high levels of integration through the inclusion of content standards from both STEM and arts disciplines, illustrated in the following quote:

However, being able to focus with [teacher name] on just the fourth grade and them saying, oh, okay, right now we're doing force and motion. I was like, "Oh, okay, cool. Simple machines." That was the other thing that we were doing. All right, this works into that standard. It works into my standard with the patterns, lines, shapes, colors.

Both quantitative and qualitative data suggest that teachers increased the frequency with which they integrated content across two or more disciplines. After one year of participation in the GoSTEAM@Tech program, more than half of the participants (53\%) reported that they "always" do this, compared to only $21 \%$ of participants on the before participating. Furthermore, after one year of participation, all teachers reported that they utilize STEAM integration in their classroom instruction at least "sometimes." This finding also emerged through the qualitative data, which suggest that teachers' overall understanding of STEAM integration changed while participating in GoSTEAM@Tech. For instance, one teacher reported on the end-of-year post-survey that "my understanding has changed because now I know STEAM is not something else we do in education, it's the lens through which we teach. It's authentic and reveling to the world around us." In a focus group, a teacher provided a definition of STEAM that addressed a common misconception and reflected the teacher's expanded definition of STEAM: 
The arts in STEAM is not just visual art. I think that a lot of teachers think that, "Oh, it's art." It's not just visual art. You can put a dance in there. You can put theater in there. You can put music in there. You can put photographer in there. There's so many different arts.

\subsubsection{Self-Efficacy}

Teaching self-efficacy was assessed through pre-post survey design, with teachers rating their general teaching self-efficacy on a nine-point scale. Generally, teaching selfefficacy was maintained throughout the first year of participation in the GoSTEAM@Tech program. There was a statistically significant difference in pre-post means for only one item assessing teaching self-efficacy. Before participating in GoSTEAM@Tech, teachers reported that, on average, they had "some influence" to "quite a bit of influence" assisting families in helping their children do well in school $(M=6.53, S D=2.00)$. After one year of participation in the program, teachers' self-efficacy increased such that they reported they had "quite a bit of influence," on average $(M=7.80, S D=1.37), t(14)=3.02, p<0.01$, $d=0.74,95 \% \mathrm{CI}[0.37,2.17]$. The moderate to large effect size for this difference suggests that this increase is meaningful in practice. End-of-year post-survey results also indicated that teachers' self-efficacy specifically related to STEAM education increased after one year of participation in GoSTEAM@Tech. Teachers indicated on a 5-point agreement scale that, after participating in one year of the program, they agreed that they have a better understanding of how to implement a STEAM lesson $(M=4.63, S D=0.62)$ and how to assess a STEAM lesson $(M=4.38, S D=0.72)$.

\subsubsection{Pedagogical Changes}

All teachers rated the impact of GoSTEAM@Tech on their professional development as either positive ( $25 \%)$ or very positive $(75 \%)$ on the end-of-year post-survey. In openended items, teachers elaborated on how their participation impacted their perceptions or practices related to specific elements of PBIL instruction, including classroom organization, lesson presentation, and curriculum. Eight teachers described changes to classroom organization as a result of participating in GoSTEAM@Tech. Half of these respondents discussed how their perception changed due to a better understanding of PBIL. For instance, one teacher mentioned, "I have learned to step back and access the entirety of the PBL assignment. I had to adjust my classroom setup to provide a physical space for learning to occur and transform."

Teachers also indicated changes to their lesson presentation and preparation, attributing their ability to successfully plan and experiment with PBIL lessons to the support and resources provided by the GoSTEAM@Tech program, including the summer PD. Many of the participants stated that they now incorporate multiple methods for presenting content to students in an effort to be "flexible", "engaging", and "creative". Teachers also mentioned the student-led nature of their lessons, describing how this approach "allowed an opportunity for students to uncover answers for themselves rather than just memorizing for a test" and how "students can be actively involved in their own learning process and can take ownership of their own learning". After implementing STEAM PBIL lessons, one teacher stated that they were inspired to revisit past lesson plans to determine if they can be taught with a STEAM-based approach. These responses suggest that seeing the positive impact of STEAM PBIL lessons on students was the catalyst for pedagogical changes for some teachers. Some teachers further noted that their school's partnership with GoSTEAM@Tech, impacted their school more broadly, encouraging their administration to support a PBIL approach.

With regard to curriculum, some respondents commented on how they have begun to emphasize the integration of multiple course curricula, with one participant stating, "I learned that our curriculum can be incorporated in projects that can allow students to learn multiple objectives at one time". Some teachers described being able to create more targeted or in-depth curriculum as a result. Two teachers considered a more flexible curriculum structure as valuable to students' learning with one stating, "now I perceive that having a 
'freeform' curriculum isn't all that bad. It allowed for me to access my students while also access myself. My lessons became more adaptive to my student's academic needs".

\subsubsection{Collaboration}

Using SNA methodology, we also explored changes in the number of collaborators and type of collaboration among teachers after one year of participation in the GoSTEAM@Tech program. The social network maps below depict the collaboration of teachers before and after participating in the first year of the program, with each numbered dot representing participants or school personnel identified as collaborators by participants (Figure 3). Before the program, the most common form of collaboration among these individuals was sharing resources and informal information exchange. After participating in GoSTEAM@Tech, the instances of reported collaboration increased slightly, as did the number of individuals within the network. This suggests that collaboration increased among teachers within the program and among GoSTEAM@Tech teachers and other personnel at their schools. Additionally, participants reported substantially more collaboration through joint work after a year in the program. The reported instances of collaboration through giving or receiving advice or help increased as well.

Before GoSTEAM@Tech

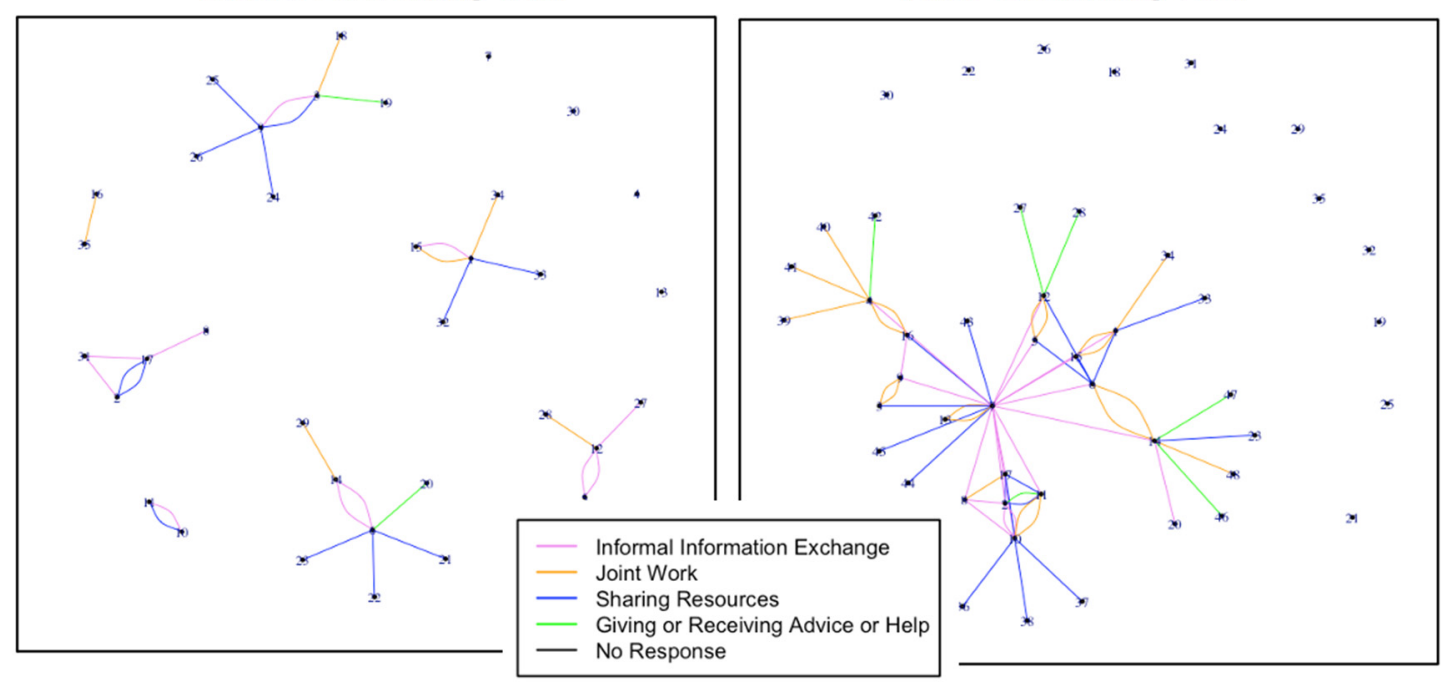

Figure 3. Collaboration before and After One Year of Participation in GoSTEAM@Tech.

In addition to exploring collaboration through social network questions, we asked teachers to rate the frequency of their STEAM-related collaboration before and after participating in their first year of the program. Before participating in GoSTEAM@Tech, about a quarter of participants reported that they never collaborated to develop interdisciplinary STEAM lessons (28\%) or collaborated to integrate STEAM topics and academic or discipline-specific topics (21\%). After one year in the GoSTEAM@Tech program, all teachers reported collaborating with other teachers at their schools in these ways at least "sometimes". This suggests that, though some teachers were already engaging in STEAMrelated collaboration before the program, all teachers were doing this after one year in the program. In open-ended post-survey items, teachers also described the nature of their STEAM-related collaboration. As one teacher indicated, "my team co-taught. We presented lessons together, and bounced ideas off of each other constantly". Another teacher stated, "I was impacted by working with a colleague to jointly access a group of students within a similar academic area. I have learned to collaboratively plan." Overall, the results showed that because of the program structure, and the integration components, teachers found opportunities to collaborate more and exchange resources. 


\subsection{Challenges Implementing STEAM}

\subsubsection{School-Level Challenges}

Teachers participating in the GoSTEAM@Tech program discussed challenges similar to those described in the STEAM literature, including challenges at the school, teacher, and student level. The school-level challenges described by teachers reflect the importance of support from school administration when implementing STEAM PBIL initiatives. Teachers indicated challenges implementing their Action Plans when they did not have common planning time to work across disciplines with the other GoSTEAM@Tech teacher at their school, replicating previous studies that have documented this challenge within STEAM education $[6,8,28]$. In a focus group, one teacher summarized how the lack of common planning time affected the implementation of Action Plans:

We had to work on our own a lot. We needed to have that collaborative planning time throughout the day. We did not, we never got it. We had to make it after school, or just kind of catch it when we could catch it kind of thing. That just made it extremely difficult. This was a big task.

In addition to challenges with common planning time, teachers also felt pressure from administrators to meet curricular demands or focus on standardized testing, which is a common challenge associated with PBL and inquiry-learning [26,27]. One teacher described in a focus group how they saw this challenge reflected in their school environment:

So, I think they [administrators] try to put so much pressure on these kids to show this growth on a test and then they forget about their experiences in the classroom and how important that is as opposed to just the importance of a test.

Another school-level challenge involved balancing multiple responsibilities. Multiple teachers in one district reported feeling "overwhelmed" by the challenge of implementing their Action Plans in the midst of other responsibilities related to school-wide initiatives, even when these other responsibilities were also related to STEM or STEAM learning.

\subsubsection{Teacher-Level Challenges}

Teachers described expected and unexpected challenges related to implementing STEAM PBIL lessons in their classes. One of these challenges was addressing learning goals and standards from multiple disciplines as part of lesson plan implementation. Challenges integrating standards across STEAM disciplines is not unique to our context (see, for example $[7,28]$ ), and teachers within our program expected that this might be a challenge within their own classrooms. As one teacher explained, standards integration remained a challenge even after preparing integrated STEAM Action Plans during the summer PD:

I think that was a challenge we anticipated, and not having done it before, we weren't sure exactly how best to integrate the standards for both classes... But I think that was one of the biggest challenges was making sure that we combined standards.

When designing their Action Plans during the summer PD, teachers took into account certain constraints related to the nature of their courses (e.g., Advanced Placement designation or class size). At multiple schools, teachers' class schedules or course load were altered after the year began. In response, teachers had to adjust the content or structure of their plans, which was challenging. Furthermore, some teachers designed STEAM PBIL lessons that they hoped would involve additional teachers or the larger school community. When the school year started, this too became a challenge. Similar to past research on teachers implementing STEAM in their schools [8], teachers within our program described the difficulty of working with fellow teachers and getting "buy in" on school-wide projects or efforts. Some teachers decided to scale back their Action Plans in response to this challenge, while others tried to continue implementing large-scale STEAM projects without the support of other teachers at their schools. One teacher likened the experience of implementing their Action Plan in this climate to being "salmon going against the stream". 


\subsubsection{Student-Level Challenges}

At the student level, teachers reported challenges tailoring their STEAM lessons to the varying needs of students. Teachers in the GoSTEAM@Tech program taught students at various levels (i.e., Advanced Placement, magnet/gifted, self-contained setting, general classroom) and teachers needed to plan for differentiated instruction to meet the needs and proficiencies of their students. Teachers also had to adjust their pacing to provide students with adequate time to engage with and master content, which is a challenge also reported in previous studies of STEAM initiatives $[8,28]$. Multiple teachers mentioned that the implementation process reinforced for them the academic areas in which their students needed support, especially in the area of literacy. As one teacher stated:

The students we teach aren't necessarily all on sixth grade reading level, or all aren't performing at a sixth-grade level. Just trying to figure out, how do I push this task on them when they're already struggling in other areas? I guess that's my take on it. It was very eye opening for me.

While teachers often described this as a challenge, it was also described as an opportunity for teachers to recognize what was necessary to meet the needs of students. Teachers tried to address differing student needs by capitalizing on individual strengths and helping their students engage with the content.

\subsection{Support Mechanisms for Addressing Challenges}

Despite challenges, various components of the GoSTEAM@Tech program (i.e., summer PD, program activities and documents, innovators, coaches) prepared and provided support to teachers, mitigating the effects of these challenges. Additionally, teachers described using creativity, communication, and flexibility to address changes, demonstrating resilience even despite challenges. The teachers indicated a commitment toward student learning that seemed to bolster their efforts, even during times of difficulty.

\subsubsection{Meaningful Professional Development}

As previously described, there were certain elements of the summer PD experience that teachers perceived as important for their success in developing and implementing STEAM PBIL lessons. During the PD, teachers completed documents that helped them prepare to implement STEAM PBIL lessons during the coming year. At the end of the year, teachers described two of these documents as useful for mitigating challenges during the school year: their Action Plan and their SWOT Analysis. The Action Plan document outlined teachers' plans for STEAM PBIL implementation for the year, including relevant standards, materials and resources needed, and responsibilities of each member of the STEAM Implementation Team in contributing to successful implementation. One teacher referred to the Action Plan as their "blueprint" for implementation. The SWOT analysis helped participants anticipate potential pitfalls or barriers to implementation relevant to their specific school context. In describing the SWOT analysis, one teacher stated that, although they knew they might encounter challenges, the SWOT analysis helped them take a proactive approach to identify threats to successful implementation of their Action Plan and strengths that might offset potential challenges.

In reflecting on their experiences in end-of-year focus groups, teachers described how elements of the PD supported them to address challenges they faced during the school year. One such challenge was finding common planning time. However, the time provided during the summer PD to collaboratively plan with their STEAM Innovation Teams was helpful in lessening this challenge, as one participant described in a focus group:

The time given, actually, during our professional development, to really sit down and really specifically and intentionally plan out what the work will look like and what the innovators will be in that work because once school starts, things can go haywire. It can get crazy and then you can lose focus if there's not a solid plan in place. I think that's definitely key. 


\subsubsection{Administrative Support}

The support of school administrators was crucial for teachers' ability to successfully implement their Action Plans. At the end of the school year, a majority of teachers agreed that, despite challenges, their school administration was supportive of GoSTEAM@Tech activities. In the end-of-year post-survey, one teacher stated that "the partnership between my school and CEISMC really allowed openness from my admin to allow me to try new things", suggesting that the involvement of an external support system for teachers made their administration more willing to engage in STEAM. In focus groups, most teachers reported that their administration was enthusiastic about participating in the GoSTEAM@Tech program. However, the school-level challenges described above indicate that enthusiasm was not enough to help teachers successfully implement STEAM PBIL at their schools. There was additional, tangible support provided to some teachers by their school's administration that allowed them to successfully mitigate challenges with implementation. For example, in some schools, teachers were given common planning time or opportunities to push into each other's classes in order to collaboratively plan and implement GoSTEAM@Tech Action Plans. Furthermore, the administration in these schools created a culture supportive of STEAM, increasing the buy-in of other teachers and allowing for greater impacts of GoSTEAM@Tech at the school level. Thus, the presence of robust administrative support bolstered implementation of STEAM PBIL.

\subsubsection{GoSTEAM@Tech Coach Support}

On the end-of-year post-survey, participants commented on their coach's ability to guide them through challenges during implementation, such as unanticipated adjustments to their Action Plans and challenges with school administration. In both surveys and focus groups, teachers described the support of their coach in helping them generate ideas for their Action Plans. One teacher described how their coach helped them form a starting point from which to build their Action Plan, stating, "as someone who has always been interested in STEAM, but didn't have know-how on where to start, having a coach gave me the extra support I needed". Coach support was especially valuable when teachers perceived a lack of administrative support and coaches served as a liaison between teachers and school administration. Coaches also connected teachers with partners and resources outside of their schools, helping minimize challenges related to accessing resources. A few teachers mentioned that their coaches motivated them to meet deadlines, stay focused, and continue forward with their Action Plans, answering questions and offering advice along the way. As former educators themselves, coaches offered empathetic support for teachers when they faced challenges, as described by one participant:

There were times that we were just completely bogged down. [Coach] kind of gave us some focus on how to look at it. "Okay, let's see what you still have left. Let's tackle this part of it. Let's make sure... " Even if it was just a voice that said, "Gosh, I see what they're doing to you. Stay focused, and I see that you're doing a good job." That was a great help.

\subsubsection{GoSTEAM@Tech Innovator Support}

Within the STEAM Innovation Team, teachers perceived innovators to be a key mechanism for classroom support. Innovators used their knowledge to assist with technology and help find solutions when problems arose, making them a key classroom-level support. On the end-of-year post-survey, one teacher summarized this support, stating that their innovator "helped us remain true to the project/Action Plan when things did not work out or we needed to change aspects of the project". When working with teachers, innovators presented novel ideas that helped teachers deliver and implement content. Teachers welcomed this expertise as they negotiated complex schedules, student needs, and curricular demands. The efforts of innovators were crucial for implementing arts content and new technology, as this quote suggests: 
Well, actually for us, I think it was a pretty good team. First out, everything was real new to me. With [Innovator] and [co-teacher] being there, they really helped out with the art integration. I wasn't really familiar, honestly with the EarSketch, outside what they did during the summertime. I'm really new to this whole thing. With [co-teacher] and [Innovator], they really helped out.

\subsubsection{Ongoing Support Needs}

In surveys and focus groups, teachers requested ongoing pedagogical support with PBIL and STEAM lesson planning and implementation. In particular, teachers reported lingering concerns about standards integration in PBIL lessons, as one teacher described:

I'm glad you brought that up because my concern was how to do that and still cover all the standards. How can I incorporate both? Stay on pace but also make sure that the lessons that I present are project-based.

In addition, teachers requested training on specific STEAM content and technologies related to coding, music, theater arts, and computer science. While there was an interest in ongoing support, survey data indicate that some teachers felt they could sustain STEAM initiatives without program support if needed. On the end-of-year post-survey, teachers were asked if they would be able to continue implementing STEAM PBIL lessons next year if they did not have GoSTEAM@Tech support (i.e., a stipend, access to resources, a professional learning community, GoSTEAM@Tech Staff). About half of the participants $(42 \%)$ reported that they felt prepared to implement STEAM PBIL lessons without assistance from GoSTEAM@Tech. They attributed this sustainability to the support they experienced throughout the year and during the summer PD. One respondent recognized the network they developed through their experience as "a great source of support" for continuing to implement STEAM PBIL lessons. Another respondent noted that STEAM integration is an expectation at their school so they would be able to continue with school support alone. These responses are encouraging and speak to confidence some teachers felt in their ability to implement STEAM PBIL lessons after participating in just one year of the GoSTEAM@Tech program.

\section{Discussion}

Amidst the enthusiasm for STEAM learning, it is crucial to understand the challenges and perspectives of those tasked with implementing STEAM instruction. Our findings from the pilot year of the GoSTEAM@Tech program contribute to the growing body of literature on STEAM education by detailing a model of STEAM teacher training and the extent to which this model was successful in supporting teachers as they worked collaboratively to design and implement STEAM lessons. We share teachers' perspectives on the important elements of STEAM teacher training, as well as the influence of participation on teachers' perceptions and practices related to STEAM. Furthermore, we document the challenges faced by teachers implementing STEAM, many of which mirrored past studies of STEAM education, as well as the ways in which a teacher training program can be designed to mitigate some of these challenges. In response to calls to clarify the definition of STEAM, we provide the definition of high-quality STEAM within our context. The results indicate that the program's STEAM definition was useful for teachers' understanding and the implementation of STEAM lesson plans. Quantitative and qualitative data suggest that teachers perceived high levels of arts integration in their Action Plans and developed a better understanding of arts integration in STEAM, despite challenges enacting integrated STEAM lessons in the classroom. In upcoming years, our goal will be to further refine our definition of STEAM and finalizing a robust STEAM teacher training program.

Through the combination of a 5-week summer PD experience and ongoing support, teachers from STEM and arts disciplines were able to collaboratively plan and implement integrated STEAM lessons. Our findings indicate that the summer PD was important for creating a shared language and pedagogical foundation that allowed teachers to bridge the content and pedagogical gap that often exists between STEM and arts classrooms. 
Furthermore, STEM and arts teachers from each school began collaborating during the PD, which allowed them to share learning and be intentional about the equal inclusion of both STEM and arts disciplines in their Action Plans. This was important for preventing one discipline from being considered an add-on, which might hinder the implementation of that discipline's content [43]. Collaborative lesson plans held each teacher accountable for trying to achieve equal integration of STEM and arts and created a sense of community among the group.

As they developed a pedagogical and collaborative foundation, teachers created their STEAM Action Plan as the culminating product of the summer PD. The Action Plan was vital for teachers' success during the school year, allowing them to articulate their plans for cross-disciplinary instruction and anticipate potential challenges. Even with careful preparation, lesson enactment is often driven by several academic and structural factors and having the ability to make modifications to meet those factors allows for greater impact in implementation [44]. Qualitative data suggest that by providing flexibility for teachers to make changes to their plan as they adjusted to their school contexts, they were empowered in the implementation process. Planning the summer PD with intentionality, modeling activities with teachers, and thinking about disciplinary roles within the project were all important to strengthen the quality of the PD and STEAM instruction.

Our findings suggest that while a 5-week summer PD experience was adequate in giving teachers a foundation in STEAM and PBIL, ongoing support was essential in helping teachers feel equipped to implement STEAM in the midst of challenges faced during the school year. Teachers benefitted from pedagogical expertise of coaches and technical expertise and classroom support from innovators. Innovators often supported the delivery of innovative lessons in the classroom and helped bridge arts and STEM content. Qualitative data suggest that having innovators present as an on-site content expert provided teachers the confidence to introduce new concepts in their classrooms. Continued collaboration was enacted in our model throughout the school year with regular meetings of the GoSTEAM@Tech Innovation teams. These meetings supported teachers in navigating and adapting their Action Plan implementation within the context of the school environment. Strong, continued collaboration helped teachers remain true to the pedagogy and content of the Action Plan.

Ongoing financial and material support allowed teachers to engage students in new and otherwise impossible ways. Many teachers have limited resources at their schools. Therefore, having access to supplemental funding from the GoSTEAM@Tech program was instrumental in the implementation of STEAM initiatives at their schools. This funding also facilitated field trips to many of the organizations highlighted in the summer PD experience. Providing students with these authentic experiences energized teachers ${ }^{\prime}$ classroom implementation of their STEAM Action Plans. The synergy of these multiple support mechanisms was essential in helping provide well-rounded support, particularly if teachers lacked robust support of school administrators or colleagues. Our findings also suggest that ongoing support from school administration is crucial when implementing STEAM initiatives at the schools. Therefore, as we design future STEAM teacher training, we need to consider ways to engage administrators throughout the PD as teachers design their Action Plans. This would allow administrators to be involved in the process and anticipate support that will need to be in place at the schools to facilitate implementation.

Our data suggest that our STEAM teacher training model may be a successful mechanism for supporting teachers' confidence and ability to implement STEAM PBIL lessons. While general teaching self-efficacy remained unchanged after one year in the program, teachers perceived an increase in their STEAM self-efficacy and an enhanced understanding of arts integration and PBIL. Qualitative data supported this, with the success of these models in engaging students contributing to a deeper understanding of how to teach STEAM, or pedagogical content knowledge [45]. Pedagogical content knowledge is the "the ways of representing and formulating the subject that make it comprehensible to others" [45] (p. 9). Additionally, these findings align with Guskey's model of teacher change, in which 
experiencing student outcomes and success contribute to teachers' attitudes and beliefs about the effectiveness of their teaching [46]. In other words, professional development and classroom practices may lead to changes in student outcomes that impact how teachers view their teaching effectiveness. As this evaluation evolves, we will continue to assess how participating in the GoSTEAM@Tech program influences teachers and their students.

The pilot year of the GoSTEAM@Tech program was essential in testing a model of STEAM teacher training that supported collaboration among teachers through a 5-week summer PD and ongoing pedagogical and financial support. After just one year in the GoSTEAM@Tech program, some teachers felt able to sustain high-quality STEAM lessons in the future without program support. This offers promising evidence that the teacher training program may be effective in supporting teachers' success collaborating across disciplines and developing STEAM pedagogical content knowledge after just one year of participation in the program. The pilot year is one of exploration and implementation and is not without its limits. Within the methodology of the study itself, our case is based on a relatively small number of participants within a unique context and setting. Our intent is to present and describe a potential case with recommendations that might enhance teacher training in STEAM in other settings and contexts. Most of our data relied on the perspectives of teachers, and we argue that their experiences and perspectives are paramount in understanding how to meet their unique professional needs. As the COVID19 pandemic occurred toward the end of our data collection, some of our findings were likely impacted by the abrupt transition to emergency remote teaching in the last months of the school year, though data collection was able to continue in a virtual format. We are exploring the implementation of our GoSTEAM@Tech model in virtual and hybrid classroom settings during the 2020-2021 school year.

The findings from this evaluation have implications for the development and evaluation of STEAM teacher training. STEAM PD may be most successful when it involves collaborative planning time for teachers across disciplines, a shared pedagogical foundation (such as PBIL), and hands-on opportunities for teachers to experience STEAM learning. Our data suggest the importance of continued support for teachers throughout the school year as they translate knowledge gained in PD into classroom practices. Evaluations of STEAM teacher training programs are critical for understanding the components that contribute to teacher and student success. Further research is needed on the mechanisms through which STEAM teacher training programs can support the adoption of STEAM PBIL pedagogies and support student success.

Author Contributions: Conceptualization, K.L.B., J.R.J., M.A., A.E.R., S.G. and M.U.; Data cu-ration, K.L.B. and J.R.J.; Formal analysis, K.L.B., J.R.J. and M.A.; Funding acquisition, M.U.; Investigation, K.L.B., J.R.J. and M.A.; Methodology, K.L.B. and M.A.; Project administration, K.L.B., J.R.J., A.E.R. and S.G.; Resources, K.L.B., J.R.J. and M.A.; Supervision, M.A. and M.U.; Visualization, K.L.B., J.R.J. and M.A.; Writing—original draft, K.L.B., J.R.J., M.A., A.E.R., S.G. and M.U.; Writing—review \& editing, K.L.B., J.R.J., M.A., A.E.R., S.G. and M.U. All authors have read and agreed to the published version of the manuscript.

Funding: This research was funded by a private foundation.

Institutional Review Board Statement: The study was conducted according to the guidelines of the Declaration of Helsinki, and approved by the Institutional Review Board of the Georgia Institute of Technology (protocol code H18481, date of approval 8 January 2019).

Informed Consent Statement: Informed consent was obtained from all subjects involved in the study.

Data Availability Statement: The data presented in this study cannot be shared due to restrictions from the funding organization.

Acknowledgments: We would like to thank the many Center faculty and staff that contributed to this program and to its evaluation. Among those, we would like to thank Emily Frobos for assistance 
with data collection and management and Isabel Goddard for assistance with data analysis. We would also like to thank the participating teachers and their students.

Conflicts of Interest: The authors declare no conflict of interest. The funders had no role in the design of the study; in the collection, analyses, or interpretation of data; in the writing of the manuscript, or in the decision to publish the results.

\section{References}

1. Land, M.H. Full STEAM ahead: The benefits of integrating the arts into STEM. Procedia Comput. Sci. 2013, 20, 547-552. [CrossRef]

2. Colucci-Gray, L.; Burnard, P.; Cooke, C.; Davies, R.; Gray, D.; Trowsdale, J. Reviewing the Potential and Challenges of Developing STEAM Education through Creative Pedagogies for 21st Learning: How can School Curricula be Broadened Towards a More Responsive, Dynamic, and Inclusive form of Education? British Educational Research Association: London, UK, 2017. [CrossRef]

3. Katz-Buonincontro, J. Gathering STE(A)M: Policy, curricular, and programmatic developments in arts-based science, technology, engineering, and mathematics education Arts Educ. Policy Rev. 2018, 119, 73-76. [CrossRef]

4. Kim, D.; Bolger, M. Analysis of Korean elementary pre-service teachers' changing attitudes about integrated STEAM pedagogy through developing lesson plans. Int. J. Sci. Math. Educ. 2016, 15, 587-605. [CrossRef]

5. Park, H.; Byun, S.-Y.; Sim, J.; Han, H.-S.; Baek, Y.S. Teachers' perceptions and practices of STEAM education in South Korea. Eurasia J. Math. Sci. Technol. Educ. 2016, 12. [CrossRef]

6. Quigley, C.F.; Herro, D. "Finding the joy in the unknown": Implementation of STEAM teaching practices in middle school science and math classrooms. J. Sci. Educ. Technol. 2016, 25, 410-426. [CrossRef]

7. Jamil, F.M.; Linder, S.M.; Stegelin, D.A. Early childhood teacher beliefs about STEAM education after a professional development conference. Early Child. Educ. J. 2018, 46, 409-417. [CrossRef]

8. Herro, D.; Quigley, C.; Cian, H. The challenges of STEAM instruction: Lessons from the field. Action Teach. Educ. 2019, 41, 172-190. [CrossRef]

9. Patton, M.Q. Developmental evaluation. Eval. Pract. 1994, 15, 311-319. [CrossRef]

10. Patton, M.Q. Utilization-Focused Evaluation; Sage Publications: Newbury Park, CA, USA, 2008.

11. Grant, J.; Patterson, D. Innovative arts programs require innovative partnerships: A case study of STEAM partnering between an art gallery and a natural history museum. Clear. House A J. Educ. Strateg. Issues Ideas 2016, 89, 144-152. [CrossRef]

12. Engelman, S.; Magerko, B.; McKlin, T.; Miller, M.; Edwards, D.; Freeman, J. Creativity in authentic STEAM education with EarSketch. In Proceedings of the 2017 ACM SIGCSE Technical Symposium on Computer Science Education, Seattle, WA, USA, 8-11 March 2017; pp. 183-188.

13. Hayman, S.L. Investigating STEAM: Integrating Art and STEM to Spark Innovation. Bachelor's Thesis, University of Arkansas, Fayetteville, NC, USA, 2017; p. 16.

14. Jeong, S.; Kim, H. The effect of a climate change monitoring program on students' knowledge and perceptions of STEAM education in the republic of Korea. Eurasia J. Math. Sci. Technol. Educ. 2015, 11, 1321-1338.

15. Kong, Y.T.; Huh, S.C.; Hwang, H.J. The effect of theme based STEAM activity programs on self efficacy, scientific attitude, and interest in science learning. Int. Inf. Inst. 2014, 17, 5153-5159.

16. Peppler, K. STEAM-powered computing education: Using e-textiles to integrate the arts and STEM. Computer 2013, 49, 38-43. [CrossRef]

17. Gross, K.; Gross, S. TRANSFORMATION: Constructivism, Design Thinking, and Elementary STEAM. Art Educ. 2016, 69, 36-43. [CrossRef]

18. Kim, S.-H.; Song, K.-S. Gifted students' perception changes toward computer science after STEAM-based CS education. J. Converg. Inf. Technol. 2013, 8, 214.

19. Liao, C.; Motter, J.L.; Patton, R.M. Tech-savvy girls: Learning 21st-century skills through STEAM digital artmaking. Art Educ. 2016, 69, 29-35. [CrossRef]

20. Lee, B.; Chang, E. A cross cultural study on STEAM education in Korea and United States. Korea Sci. Art Forum 2017, 30, 277-288. [CrossRef]

21. Ge, X.; Ifenthaler, D.; Spector, J.M. Moving forward with STEAM education research. In Emerging Technologies for STEAM Education; Springer International Publishing: Cham, Switzerland, 2015; pp. 383-395. [CrossRef]

22. Perignat, E.; Katz-Buonincontro, J. STEAM in practice and research: An integrative literature review. Think. Ski. Creat. 2019, 31, 31-43. [CrossRef]

23. Bresler, L. The subservient, co-equal, affective, and social integration styles and their implications for the arts. Arts Educ. Policy Rev. 1995, 96, 31-37. [CrossRef]

24. Bequette, J.W.; Bequette, M.B. A place for art and design education in the STEM conversation. Art Educ. 2015, 65, 40-47. [CrossRef]

25. Quigley, C.F.; Herro, D.; King, E.; Plank, H. STEAM designed and enacted: Understanding the process of design and implementation of STEAM curriculum in an elementary school. J. Sci. Educ. Technol. 2020, 29, 499-518. [CrossRef]

26. Quigley, C.; Marshall, J.C.; Deaton, C. Challenges to inquiry teaching and suggestions for how to meet them. Sci. Educ. 2011, 20, 55-61.

27. Savery, J.R. Overview of problem-based learning: Definitions and distinctions. Essent. Read. Probl. Based Learn. Explor. Extending Leg. Howard S. Barrows 2015, 9, 5-15. 
28. Herro, D.; Quigley, C. Exploring teachers' perceptions of STEAM teaching through professional development: Implications for teacher educators. Prof. Dev. Educ. 2016, 43, 416-438. [CrossRef]

29. Opperman, A. Maker education: The STEAM playground. Steam J. 2016, 2, 1-5. [CrossRef]

30. DeJarnette, N.K. Implementing STEAM in the early childhood classroom. Eur. J. Stem Educ. 2018, 3. [CrossRef]

31. Yakman, G. STEAM education professional development practicum \& research. In Proceedings of the PATT 34: Proceedings of the Pupils Attitudes toward Technology Meeting, Philadelphia, PA, USA, 11 July 2017; pp. 285-295.

32. Herro, D.; Quigley, C.; Jacques, L.A. Examining technology integration in middle school STEAM units. Technol. Pedagog. Educ. 2018, 27, 485-498. [CrossRef]

33. Thompson, C.J.; Barber, K.; Bourget, E.M. STEAM (Science, Technology, Engineering, Art, and Mathematics) education and teachers' pedagogical discontentment levels. People Int. J. Soc. Sci. 2018, 4, 496-518. [CrossRef]

34. Stock, P.; Burton, R.J. Defining terms for integrated (multi-inter-trans-disciplinary) sustainability research. Sustainability 2011, 3, 1090-1113. [CrossRef]

35. Patton, M.Q. Evaluation, knowledge management, best practices, and high quality lessons learned. Am. J. Eval. 2001, 22, 329-336. [CrossRef]

36. Honey, M.; Pearson, G.; Schweingruber, H.A. STEM Integration in K-12 Education: Status, Prospects, and an Agenda for Research; National Academies Press: Washington, DC, USA, 2014; Volume 500.

37. Creswell, J.W.; Plano Clark, V.L. Designing and Conducting Mixed Methods Research; Sage Publications, Inc.: Thousand Oaks, CA, USA, 2007.

38. Yin, R.K. Case study Research: Design and Methods (Applied Social Research Methods); Sage Publications: Thousand Oaks, CA, USA, 2014.

39. Tschannen-Moran, M.; Hoy, A.W. Teacher efficacy: Capturing an elusive construct. Teach. Teach. Educ. 2001, 17, 783-805. [CrossRef]

40. Grbich, C. Qualitative Data Analysis: An Introduction; SAGE: London, UK, 2013.

41. Saldaña, J. The Coding Manual for Qualitative Researchers; SAGE Publications Limited: Newbury Park, CA, USA, 2021.

42. Borgatti, S.P.; Ofem, B. Overview: Social network theory and analysis. In Social Network Theory and Educational Change; Daly, A., Ed.; Harvard Education Press: Cambridge, MA, USA, 2010; pp. 17-29.

43. Quigley, C.F.; Herro, D.; Jamil, F.M. Developing a conceptual model of STEAM teaching practices. Sch. Sci. Math. 2017, 117, 1-12. [CrossRef]

44. Remillard, J.T.; Heck, D.J. Conceptualizing the curriculum enactment process in mathematics education. Zdm 2014, 46, 705-718. [CrossRef]

45. Shulman, L.S. Those who understand: Knowledge growth in teaching. Educ. Res. 1986, 15, 4-14. [CrossRef]

46. Guskey, T.R. Professional development and teacher change. Teach. Teach. 2002, 8, 381-391. [CrossRef] 